Emerald Journal of Forensic Practice

\title{
Sexual Offending Hierarchies, Personality Attributions, and the Clinical Implications.
}

\begin{tabular}{|r|l|}
\hline Journal: & Journal of Forensic Practice \\
\hline Manuscript ID & JFP-07-2016-0031.R2 \\
\hline Manuscript Type: & Research Paper \\
\hline Keywords: & $\begin{array}{l}\text { sexual offender, hierarchy, personality characteristics, perceptions, } \\
\text { attributions, attitudes }\end{array}$ \\
\hline \multicolumn{2}{|l}{} \\
\hline
\end{tabular}

SCHOLARONE

Manuscripts 


\title{
Sexual Offending Hierarchies, Personality Attributions, and the Clinical Implications.
}

\begin{abstract}
Aims: the research examines sexual offending hierarchies constructed by the general public and forensic staff based on personal attitudes and perceived severity of offence. In addition, six sexual offence perpetrators are differentiated using the Five Factor Model of personality.

Method: vignettes represented six sexual offence perpetrators. Participants built a hierarchy based on perceived severity of offence, before attributing personality characteristics to each offender using a Likert-type scale.

Results: contact offenders were perceived as more dangerous than non-contact offenders. Rapists were perceived as the most dangerous, and voyeurs the least dangerous. Offenders were attributed significantly different personality traits. Generally, men who sexually offend are perceived to be low in agreeableness, openness and conscientiousness and high in impulsivity, manipulativeness and neuroticism.
\end{abstract}

Practical Implications: the research highlights the importance of individual risk assessment in determining best practice treatment for men who have sexually offended. The Five Factor Model has been proven to be a useful tool to explore the impact staff attitudes have on risk assessment and treatment. Low-risk and highrisk men who have sexually offended would benefit from divergent treatment. Consideration should be given to personality characteristics in addition to level of risk. 
Originality: The research determines a hierarchy of men who sexually offend, and goes beyond the 'label' of sexual offenders to explore how personality impacts on formation of attitudes.

Keywords: sex offender; hierarchy; personality characteristics; perceptions; attributions.

\section{Article Classification: Research Paper}

\section{Introduction}

Attitudes towards offenders has been a frequent research interest for many years. Attitudes towards men who have sexually offended (MSO) became a research interest in the 1990s, instigating the development of the Attitudes Towards Sex Offenders scale (ATS; Hogue, 1993). This initiated research into attitudes towards MSO, (e.g. Hogue, 1993; Hogue \& Peebles, 1997). From an internal perspective, MSO have been found to have more positive attitudes towards their own offender group (Hogue, 1993). From an external perspective, the literature supports an "exposure equates to more positive attitudes" argument, with an emphasis on the importance of job role (Hogue, 1993). The importance of understanding and exploring the attitudes of those who work with MSO is highlighted in theories that outline the desistance process, and the factors that contribute to effective desistance, including the role that staff play in therapeutic treatment and reintegration. Both the Integrated Theory of Desistance from Sexual Offending (ITDSO; Gobbels, Ward \& Willis, 2012) and the responsivity principle of the RiskNeed-Responsivity model (RNR; Andrews \& Bonta, 2010) highlight the importance 
of staff in the treatment and desistance process; thus we must understand this process, and make the necessary changes to maintain desistance. The importance of exploring sexual offending is emphasised by evidence that suggests recidivism increases if ex-offenders are not adequately supported upon release into the community (Laws \& Ward, 2011) to access basic primary goods as outlined by the Good Lives Model (GLM; Ward \& Maruna, 2007).

Previous attitudinal research focuses on the label of 'sex offender', rather than characteristics such as personality. This results in MSO being defined by their offence in a way that other offenders do not appear to become defined. Research has found that using the label of 'sex offender' created attitudes that strengthen public support for the use of policies to manage MSO, and strongly influence the way in which the public perceive offenders (Harris \& Socia, 2014). Introducing a label of paedophilia to vignettes results in more punitive attitudes against MSO, in comparison to a description of men having a 'sexual interest in children' (Imhoff, 2015). This highlights the importance of labels in the formation of attitudes, but also raises the issue of misrepresentation of sex crimes in the media, and the influence this has on the development of attitudes. The media's portrayal of sex crimes can have implications on the way in which MSO are perceived. The media sensationalise sex crimes (e.g. Harper and Hogue, 2014 ) and over represents them (Harper and Hogue, 2014 ${ }^{\mathrm{b}}$ ). This provides the public with misleading information about MSO, falsely informing perceptions. 
Hierarchies among prisoners are important concepts; "I vividly remember in Belmarsh, how viciously the 'nonces' were verbally abused by the straight men of violence - armed robbers, arsonists, and murderers, who felt themselves morally superior to the sex offenders" (Aitken, 2014; Evening Standard). The quote suggests that MSO fall within the inferior range of an offender hierarchy. It must be considered whether it is appropriate to house MSO on the same wings as other offenders in general prisons, and whether treating all MSO together is the most effective method of relapse prevention. Within therapy, Cowburn (1990) found that the anticipated hierarchy of rapists feeling superior to child molesters did not develop; concluding that it was useful to have a heterogeneous group in order to reduce collusion regarding beliefs and attitudes. Adult abuser only groups results in increased cohesiveness and active participation compared to mixed offender groups (Allam et al., 1997). It is therefore important to consider how MSO are different. Low agreeableness, low extroversion, and high neuroticism have all been found to significantly correlate with anti-social behaviours and criminality (Blackburn \& Coid, 1998). In addition, Cale (2006) attributed impulsivity to anti-social behaviours, thus suggesting offenders may be low in conscientiousness. More specifically, MSO are low in extroversion, conscientiousness, openness, and agreeableness, and high in neuroticism (Carvalho \& Norbe, 2013; Becerra-Garcia et al., 2013; Voller \& Long, 2009; Egan et al., 2005; Dennison et al., 2001; Rapaport \& Brukhart, 1984; Rader, 1977). Some other prominent traits that are highlighted in the research include impulsivity and manipulation. There were some variations in attributions to traits, for example Voller and Long (2009) concluded that sexual assault perpetrators 
were more similar to non-perpetrators than to rape perpetrators, and Carvalho and Norbe (2013) identified child molesters to be lower in openness than rapists.

The current research proposes that hierarchies developed by the general public and forensic staff will significantly differ, and thus, support the exposure argument. It is also hypothesised that attributions of personality will significantly differ depending on the description of the offender.

\section{Method}

\section{Participants}

Participants were recruited from two populations; the general public and staff working within forensic healthcare with MSO. A total of 226 participated; 112 from the general population ( $78 \%$ female, $22 \%$ male) and 114 forensic staff $(76.3 \%$ female and $23.7 \%$ male). Twenty-five general public data and forty-five forensic staff data were removed from the hierarchy analysis due to incorrect responding. A power analysis indicated that 140 participants were required to detect a large effect size. Justification was based on the clinical need to see a large enough difference in attributions between each description to determine the importance of the role of attitudes in influencing risk assessment and treatment.

\section{Materials}

The research used vignettes to represent six MSO. Vignettes were developed based on the types of sex crimes that are represented in the media. Effects of variables other than offence type were controlled for by not including the age, the conviction history, and the ethnicity of the offender. Stage two of the study used the same six vignettes and seven different types of personality characteristics, based on the 
FFM. Two additional personality characteristics were included (manipulativeness and impulsivity); both of which have been found to be related to sexual offending (e.g. Becerra-Garcia et al., 2013).

\section{Procedure}

Stage one involved participants developing a hierarchy of MSO based on the vignettes by responding on a Likert-type scale from 1-6 $(1=$ most dangerous, $6=$ least dangerous). In stage two participants were required to attribute each personality characteristic to the description based on how much or little they thought that characteristic related to that offender. Presentation order of the vignettes was randomised to counteract any order effects. Participants were adequately debriefed. Anonymity was maintained throughout.

\section{Results}

\section{Sex Offender Hierarchy}

Data were analysed using a one-way analysis of variance (ANOVA). No significant differences were found between the two sample populations $(p=.369-.926)$, therefore data were amalgamated. Contact offenders were perceived to be more dangerous than non-contact offenders. Figure one demonstrates the hierarchy with the most dangerous from the left to the least dangerous on the right. Figure one incorporates attributions of personality, with the most associated at the top, working down to the least associated. 


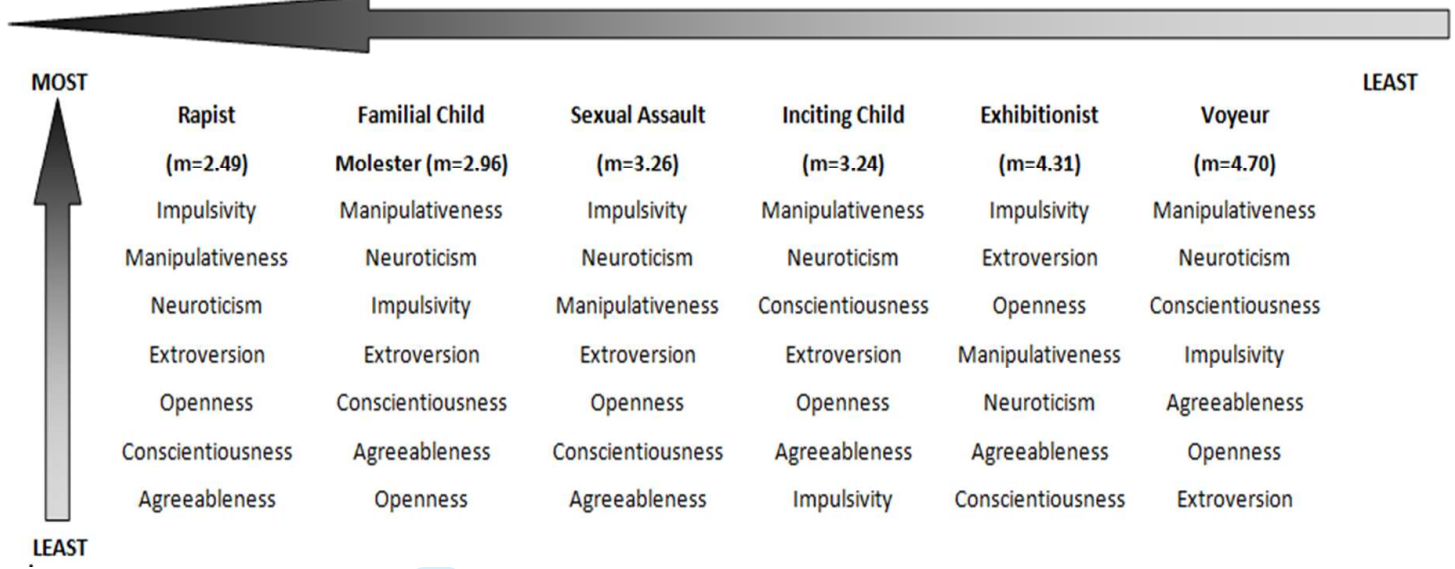

Figure 1. Offender Hierarchy and attributed personality characteristics

\section{Personality Characteristics}

No significant differences were found between groups and data were analysed together using a repeated measures ANOVA. Overall, the analysis evidences that participants perceived different offence perpetrators to have different personality characteristics. Presentation order of the vignettes did not have an effect on responses. There was no significant main effect of gender. All personality characteristics were found to have a significant main effect; therefore post-hoc pairwise comparisons were conducted to determine where the significant differences were. Figure one provides an overview of the attributed personality characteristics for each perpetrator. Impulsivity or manipulativeness was found to be the most associated personality characteristics for all offenders. Although in most cases the alternative characteristic was attributed fairly closely after, the exception to this is for those offenders who incite children via the internet. Participants perceived these offenders to be highly manipulative, but extremely low 
in impulsivity. Figure one evidences that rape and sexual assault perpetrators are perceived to be very similar in their personality characteristics, whilst most other offenders vary in their attributions, regardless of their perceived level of dangerousness.

\section{Discussion}

The research provides a hierarchy of MSO and evidences significantly different attributions of personality characteristics to different MSO based on participant's perceptions of each perpetrator. Although the current research supports the general findings within the literature that contact offenders are perceived to be more dangerous than non-contact offenders, the research does not support the exposure argument. The hierarchy reported reflects the hierarchy of criminal sanctions for sexual offences within the UK (Sexual Offence Act, 2003). It may be that participants were aware of the criminal sanctions, and responded in this way to be perceived as 'politically correct'; this would provide one explanation for the lack of significant difference between participant groups.

The research highlights the perceived differences in personality characteristics of MSO. Despite previous research suggesting that sexual assault perpetrators are more similar to non-offenders than to rape perpetrators (Voller \& Long, 2009), the current research suggests that when looking at personality attributions, rape and sexual assault perpetrators are perceived to be similar in their personality characteristics. In comparison to previous research, the current results support the findings in the literature that MSO are low in agreeableness, openness and 
conscientiousness and high in neuroticism (Carvalho \& Norbe, 2013; Becerra-Garcia et al., 2013; Voller \& Long, 2009; Egan et al., 2005; Dennison et al., 2001; Rapaport \& Brukhart, 1984; Rader, 1977). As a result of the differences in perceived personality characteristics, careful consideration should be given to the impact of these attitudes on therapeutic treatment and supervision of sexual offenders in community and forensic settings.

The findings evidence that we perceive MSO to vary in level of risk and personality characteristics dependent upon the offence committed. This suggests we must carefully consider the implications of these characteristics on treatment. As discussed, the literature and the current research demonstrate that MSO are perceived to be low in agreeableness; this perception may impact on staff expectations of a group of MSOs' abilities to form group cohesion, instilling therapeutic nihilism. Linked to this, voyeurs were attributed significantly lower levels of extroversion than other offenders; this may also impact on one's ability to engage with a group and form cohesion; thus voyeurs may benefit more from individual intervention. Group cohesion is vital to create an environment conducive to disclosure (Beech \& Hamilton-Giachritsis, 2005). However, those perceived to be low in openness may find it difficult to disclose their offending behaviour, particularly if they are also low in extroversion and agreeableness, as the MSO are perceived to be in the current study. Those assessed as being low in agreeableness and neuroticism may benefit from more intense victim awareness and empathy modules. On the other hand, if offenders were assessed as highly neurotic, a group programme may not be a suitable environment for them due to having a low 
tolerance for stress; these offender types may be more vulnerable to difficulties in managing negative emotions during disclosure sessions. Furthermore, low conscientiousness may be perceived to have an impact on MSOs' desire to affect change to their attitudes, cognitions and offending behaviours, therefore this must be considered prior to treatment engagement, as this will provide therapists with more insight regarding readiness to change. If offenders are assessed as being highly manipulative, these offenders will require firm boundaries and management to prevent manipulation of facilitators and other group members.

Previous research has suggested that high-risk and low-risk MSO require differing intensities of treatment (Mailloux et al., 2003) based on the risk and need principles of the RNR model (Andrews \& Bonta, 2010). Mailloux et al., (2003) found that over-treating low-risk MSO can have a negative impact. This raises issues of contamination (i.e. placing high-risk MSO in therapy with low-risk MSO and disclosure issues), which could result in higher recidivism rates for low-risk sexual offenders. The current research supports the argument that MSO are perceived as qualitatively different, and therefore highlights the importance of individual risk assessment prior to referral to treatment programmes. Despite evidence to suggest that the advantages of group treatment outweighs the disadvantages (Ware et al., 2009), there is no evidence to suggest that individual treatment is less advantageous than group treatment. However, what must be considered is that group-based treatments are the norm in sex offender treatment (Ware et al., 2009) and therefore understanding the similarities and differences between different perpetrators is important in determining best practice. 
Careful consideration should be given to the findings from the current research; it is important not to over-interpret the findings to go beyond what they tell us, i.e. what other people think about MSO. However, they do highlight that consideration should be given to the potential impact of staff attitudes on treatment. The characteristics discussed may result in staff perceiving MSO negatively, which can impact on therapeutic alliance and resultant willingness to change.

The findings highlight the need for individual risk assessment due to the perceived differences between perpetrators. Future best practice delivery of SOTPs may treat one type of offence perpetrator per group, i.e. one group of sexual assault perpetrators, one group of voyeurs and so on. However, it may not be costeffective or feasible to run offender-specific groups and therefore individual risk assessment is crucial. Offender-specific groups may encourage cohesion by eradicating the hierarchy and associated hostility amongst different perpetrators. This may reduce re-offending; meta-analyses have shown that increased cohesion in group psychotherapy is a predictor for positive outcomes (Burlingame et al., 2011). However, the importance of perceived personality characteristics comes in to play; those thought to be low in agreeableness and openness may impede a group's ability to become cohesive, thus, impacting on treatment effectiveness. Previous research into group cohesion suggests increased levels of agreeableness encourages group cohesion and emphasises positive outcomes (Van Vianen \& De Dreu, 2001). Finally, as the research suggests that qualitative characteristics are important in developing attitudes regarding MSO, we need to move beyond the 
convenience of using a label. Despite labels being unambiguous, they also unnecessarily define a person by their behaviour. It may be beneficial for staff working with MSO to engage in a narrative-based intervention to challenge thin narratives, to build thicker more meaningful narratives. This would impact on attitudes towards MSO.

There are inevitably limitations in the current study. Whilst convenience and snowballing methods of recruitment are suitable and cost-effective, it is limited to participants that are found within those specific groups, employed in certain areas, or residing in certain geographical locations. Consequently, participants were mostly females, which may be as a result of the composition of females within forensic healthcare. Females may be more willing to participate in research. Utilising snowball and opportunistic methods of recruitment results in difficulties determining accurate response rates. A further limitation of the research or at least a consideration for the implications of the results is whether the attributions of personality describe the participants better than they describe what we think about MSO. The results may provide more information about what participants think about MSO and the wider world, rather than what MSO and the wider world are actually like. Results require interpretation with caution as a result. Making inferences about a population based on others' views of them is not the most reliable or informative methodological approach.

Future research could provide a valuable addition to the literature by comparing people's perceptions of different types of rape scenarios. This would increase 
knowledge regarding the importance of labels and determine whether labels or context are important when developing attitudes towards offenders. Similarly, this study could be manipulated to compare different types of offence perpetrators, for example offences against minors (inclusive of MSO against children outside of the family), to determine the importance of context and labels. It may also be useful to integrate blame attribution into these studies or to manipulate the gender of the offender. Furthermore, future research may also consider the relationship between the personality characteristics attributed to each offender. It may be that there are correlations amongst the personality types. It would be valuable to further examine the differences between sexual offence perpetrators as the current research does indicate some relationships. Finally, the most accurate data of sexual offending hierarchies may come from MSO themselves. As discussed in the introduction, there appears to be a hierarchy within prisons. However, Cowburn (1990) found that in a group therapy setting, the anticipated hierarchy did not form. It would be useful to ask MSO themselves about the perceived hierarchy amongst the offender group. Unfortunately, due to ethical constraints, this was not possible within the timeframe of the current research.

The research concludes that a hierarchy can be built based on participants' attitudes towards MSO. Contact offenders were perceived to be more dangerous than non-contact offenders. The research highlights the importance of individual risk assessment based on the RNR principles (Andrews \& Bonta, 2010). The research shows that MSO are considered to be qualitatively different based on attributions of personality from the FFM (McCrae \& Costa, 1997). This highlights the 
importance of individual risk assessment, but also the importance of consideration for group treatment. The research concludes that treatment groups could be improved by being tailored for specific perpetrators. This may extinguish hierarchy, hostility, and potential contamination, but also increase cohesiveness, which has been found to be a predictor of positive treatment outcomes (Burlingame, et al., 2011). The research suggests that the FFM is a useful tool in determining appropriate treatment for individual offenders.

\section{Implications for Practice:}

- MSO require a thorough risk assessment process to determine suitability for SOTP, dependent upon level of risk and personality characteristics which may impede on group processes or therapeutic alliance.

- Staff attitudes have the ability to impact upon therapeutic engagement and treatment outcomes; thus, staff should engage in interventions to encourage consideration of the effects of negative attitudes. 


\section{References}

Aitken, J (2014), "The best way to do time for two different crimes", London Evening Standard, 8 July.

Allam, J., Middleton, D., and Browne, K (1997), "Different clients, different needs? Practice issues in community-based treatment for sex offenders", Criminal Behaviour and Mental Health, Vol. 7 No. 1, pp. 69-84.

Andrews, D. A., and Bonta, J (2010), The Psychology of Criminal Conduct. Elsevier, Amsterdam.

Becerra-Garcia, J.A., Garcia-Leon, A., Muela-Martinez, J.A. and Egan, V (2013), "A controlled study of the big five personality dimensions in sex offenders, non-sex offenders and non-offenders: relationship with offending behaviour and childhood abuse", The Journal of Forensic Psychiatry and Psychology, Vol. 24 No. 2, pp. 233246.

Beech, A. R., \& Hamilton-Giachritsis, C. E (2005) "Relationship between therapeutic climate and treatment outcome in group-based sexual offender treatment programmes", Sexual Abuse: a Journal of Research and Treatment, Vol. 17 No. 2, pp. $127-140$.

Blackburn, R., and Coid, J. W (1998), "Psychopathy and the dimensions of personality disorder in violent offenders", Personality and Individual Differences, Vol. 25 No. 1, pp. 129-145.

Burlingame, G. M., McClendon, D. T., and Alonso, J (2011), "Cohesion in group therapy", Psychotherapy, Vol. 48 No. 1, pp. 34.

Cale, E.M (2006), "A quantitative review of the relations between the 'Big 3' higher order personality dimensions and antisocial behaviour", Journal of Research in Personality, Vol. 40 No. 3, pp. 250-284.

Caringella-MacDonald, S (1998) "The relative visibility of rape cases in national popular magazines", Violence against Women, Vol. 4 No. 1, pp. 62-80.

Carvalho, J. and Nobre, P.J (2013), "Five-Factor Model of personality and sexual aggression", International Journal of Offender Therapy and Comparative Criminology, 0306624X13481941. 
Cowburn, M (1990), "Work with male sex offenders in groups", Groupwork, Vol. 3, pp. $156-171$.

Dennison, S. M., Stough, C., and Birgden, A (2001), "The big 5 dimensional personality approach to understanding sex offenders", Psychology, Crime and Law, Vol. 7 No. 1-4, pp. 243-261.

Egan, V., Kavanagh, B., and Blair, M (2005), "Sexual Offenders against children: the influence of personality and obsessionality on cognitive distortions", Sexual abuse: a Journal of Research and Treatment, Vol. 17 No. 3, pp. 223-240.

Ferguson, K., and Ireland, C (2006), "Attitudes towards sex offenders and the influence of offence type: a comparison of staff working in forensic settings and students", Journal of Forensic Practice, Vol. 8 No. 2, pp. 10-19.

Gobbels, S., Ward, T., and Willis, G.M (2012), "An integrative theory of desistance from sex offending", Aggression and Violent Behaviour, Vol. 17 No. 5, pp. 453-462.

Graber, D. A (1980), Crime News and the Public. Praeger, New York.

Grubin, D., 1998. Sex offending against children: Understanding the risk (Vol. 99). London, United Kingdom: Home Office, Policing and Reducing Crime Unit, Research, Development and Statistics Directorate.

Harper, C.A. and Hogue, T.E (2014 ${ }^{\mathrm{a}}$ ), "A prototype-willingness model of sexual crime discourse in England and Wales", The Howard Journal, Vol. 53 No. 5, pp. 511-524.

Harper, C.A. and Hogue, T.E (2014 $\left.{ }^{\mathrm{b}}\right)$, "The emotional representation of sexual crime in the national British press", Journal of Language and Social Psychology, $0261927 \times 14544474$.

Harris, A.J. and Socia, K.M (2014), "What's in a name? Evaluating the Effects of the "sex offender" label on public opinions and beliefs", Sexual Abuse: A Journal of Research and Treatment, 1079063214564391.

Higgins, C., and Ireland, C (2009), "Attitudes towards male and female sex offenders: a comparison of forensic staff, prison officers and the general public in Northern Ireland", The British Journal of Forensic Practice, Vol. 11 No. 1, pp. 14-19. 
Hogue, T.E (1993), "Attitudes towards prisoners and sex offenders", Clark, N. C and Stephenson, G, DCLP Occasional Papers: Sexual Offenders, British Psychological Society, Leicester.

Hogue, T. E., and Peebles, J (1997), "The influence of remorse, intent and attitudes toward sex offenders on judgments of a rapist", Psychology, Crime and Law, Vol. 3 No. 4, pp. 249-259.

Home Office (2012), "Registered Sex Offenders", available at: https://www.gov.uk/government/publications/registered-sex-offenders (accessed March 31 2014).

Imhoff, R (2015), "Punitive attitudes against paedophiles or persons with sexual interest in children: does the label matter?" Archives of Sexual Behaviour, Vol. 44 No. 1, pp. 35-44.

Kjelsberg, E., Skoglund, T.H., and Rustad, A.B (2007), "Attitudes towards prisoners, as reported by prison inmates, prison employees and college students", BMC Public Health, Vol. 7 No. 1, pp. 1-9.

Laws, D. R., and Ward, T (2011), Desistance from sex offending: Alternatives to throwing away the keys, New York, The Guilford Press.

Mailloux, D.L., Abracen, J., Serin, R., Cousineau, C., Malcolm, B. and Looman, J (2003), "Dosage of treatment t sexual offenders: are we overprescribing?" International Journal of Offender Therapy and Comparative Criminology, Vol. 47, pp. 171-184.

Marsh, H (1991), "A comparative analysis of crime coverage in newspapers in the United States and other countries from 1960 to 1989: A review of the literature", Journal of Criminal Justice, Vol. 19, pp. 67-80.

McCrae, R. R., and Costa, P. T (1987), "Validation of the five-factor model of personality across instruments and observers", Journal of Personality and Social Psychology, Vol. 52 No. 1, pp. 81-90.

McCrae, R.R., and Costa Jr, P.T (1997), "Personality Trait Structure as a human universal", American Psychologist, Vol. 52 No. 5, pp. 509-516.

McCrae, R. R., and Costa Jr, P. T (1999), "A five-factor theory of personality", Handbook of personality: Theory and research, Vol. 2, pp. 139-153. 
Melvin, K. B., Gramling, L. K., and Gardner, W. M (1985), "A scale to measure attitudes toward prisoners", Criminal Justice and Behaviour, Vol. 12 No. 2, pp. 241253.

Meyers, M (1997), News coverage of violence against women: Engendering blame, Sage, Thousand Oaks, CA.

Office for National Statistics. (2015), "Crime in England and Wales, Year Ending December 2015", available at:

http://www.ons.gov.uk/peoplepopulationandcommunity/crimeandjustice/bulletins/c rimeinenglandandwales/yearendingdecember2015\#sexual-offences (accessed 30 June 2016).

Rader, C.M (1977), "MMPI profile types of exposers, rapists and assaulters in a court services population", Journal of Consulting and Clinical Psychology, Vol. 45, pp. 61-69.

Rapaport, K. and Burkhart, B.R (1984), "Personality and attitudinal characteristics of sexually coercive college males", Journal of Abnormal Psychology, Vol.93, pp. 216-221.

Sexual Offences Act 2003, c. 42. (United Kingdom).

Simon, S (2010), "Psychologists' attitudes towards sex offenders", Unpublished Manuscript, Master's thesis, Pacific University. Available at:

http://commons.pacificu.edu/spp/173.

Soothill, K., and Walby, S (1991), Sex crime in the news, Routledge, London.

Van Vianen, A. E., and De Dreu, C. K (2001), "Personality in teams: Its relationship to social cohesion, task cohesion, and team performance", European Journal of Work and Organizational Psychology, Vol. 10 No. 2, pp. 97-120.

Voller, E.K. and Long, P.J (2009), "Sexual assault and rape perpetration by college men: The role of the Big Five personality traits", Journal of Interpersonal Violence, Vol. 25 No. 3, pp. 457-480.

Ward, T., and Maruna, S (2007), Rehabilitation: Beyond the risk paradigm, Routledge, London. 
Ware, J., Mann, R.E. and Wakeling, H.C (2009), "Group versus individual treatment: What is the best modality for treating sexual offenders?" Sexual Abuse in Australia and New Zealand, Vol. 1 No. 2, pp. 70-78. 